\title{
LEITURAS DA PAISAGEM: Jardim do Seridó/RN em foco ${ }^{l}$
}

\section{READINGS OF THE LANDSCAPE: Jardim do Seridó 's in focus.}

\section{LECTURAS DEL PAISAJE: Jardim do Seridó en foco.}

\author{
Evaneide Maria de Melo \\ Mestre em Geografia pelo Programa de Pós Graduação e \\ Pesquisa em Geografia - PPPGe/UFRN \\ R. Professor Melo. No 2952. Q.6, B.C, apt. 202. \\ Capim Macio/Natal-RN. CEP: 59078-580. \\ evita_melo@hotmail.com
}

\begin{abstract}
Resumo
A paisagem é uma prática social que se sobressai nas formas de representação. Sob esse aspecto, é preciso tratá-la não só como um achado visual, sendo evidente que a própria identidade da paisagem emerge de sua visualidade, mas como produtora de significados que compõem o imaginário coletivo sociocultural. Desse modo, objetiva-se aqui "ler" a paisagem citadina de Jardim do Seridó/RN tomando como referência o acervo fotográfico produzido por José Modesto de Azevedo (Zé Boinho).

Palavras-chave: Paisagem, Fotografia, Imaginário e Jardim do Seridó/RN.
\end{abstract}

\begin{abstract}
The landscape is a social practice and has been an important subject within many forms of representation. That is why it is necessary not to consider it only in its visual aspect, though it is evident that its identity relates to its visuality, but also as a producer of social and cultural collective imagination. Thus, this paper intends to "read" and analyze the images of Jardim do Seridó's landscape through the photographs of José Modesto de Azevedo (Zé Boinho).

Word-key: Landscape, Photograph, Imaginary e Jardim do Seridó's.

\section{Extracto}

El paisaje es una práctica social y ha sido un tema importante dentro de muchas formas de representación. Ése es porqué es necesario no considerarlo solamente en su aspecto visual, aunque es evidente que su identidad se relaciona con su visuality, pero también

\footnotetext{
${ }^{1}$ Pesquisa inserida na Linha de abordagem "Identidade e Representações Culturais", sob orientação da Prof. ${ }^{\text {D }}$..${ }^{\text {a }}$ Maria Helena Braga e Vaz da Costa.
} 
como productor de la imaginación colectiva social y cultural. Así, este papel piensa "leído" y analiza las imágenes hace el paisaje de Jardim do Seridó a través de las fotografías de José Modesto de Azevedo (Zé Boinho).

Palabra-llave: El paisaje, fotografía, e imaginaria Jardim do Seridó.

\title{
Paisagem como representação: abordagem cultural geográfica.
}

\begin{abstract}
Assim, agradeciamos por nossa árvore de papel como se ela fosse descendente da árvore da Vida, guardada no Jardim do éden por um anjo que empunha uma espada flamejante, segundo nos dizem as Escrituras. [...] E, se a visão que uma criança tem da natureza já pode comportar lembranças, mitos e significados complexos, muito mais elaborada é a moldura através da qual nossos olhos adultos contemplam a paisagem.
\end{abstract}

Simon Schama. 1996.

A epígrafe acima anuncia o percurso pelo qual se investiga a paisagem geográfica, na medida em que ela [a paisagem] se institui enquanto campo, instância, e lugar de conhecimento; tendo múltiplos significados que se alimentam a partir das formas de representações que são elaboradas acerca do espaço praticado, sentido, observado. Tem-se com isso, que a leitura da paisagem não deriva de uma força universal, ao contrário, é decorrência das interpretações, das apreciações, e das formas de produção de significados com as quais as sociedades estão envolvidas culturalmente.

O entendimento que se faz sobre paisagem tem relação direta com o pensamento de Duncan (2004, p. 92). Na medida em que, esse autor destaca que só é possível considerar a leitura da paisagem enquanto um sistema cultural permeado por signos, emergentes e localizados na vida social. É essencial considerar a paisagem enquanto um processo cultural condicionado por um sentido a partir do qual se tem seletividades, condicionando e sendo condicionada por valores. Assim, ele elucida:

Embora as paisagens tenham sido tradicionalmente reconhecidas como reflexos da cultura dentro da qual foram construídas, ou como uma espécie de indícios produzindo "rastros" de artefatos relacionados a acontecimentos do passado, especialmente de difusão, só raramente elas foram reconhecidas como elementos de reprodução e transformação cultural (ibdem, p. 92). 
Duncan (2004) coloca a paisagem como questão central às interpretações sígnias. Uma paisagem para ele ganha dimensão a partir de sistemas de valores, da produção de sentidos, permeada por discursos políticos, religiosos, sociais, econômicos, simbólico-imaginários, e essa é a noção da qual se vale para a concretização desse debate. De maneira que, pensar a paisagem é relacioná-la aos símbolos, signos e representações da vida social. Em Duncan (2004) fica patente que a paisagem não é vista como um dado, como uma realidade objetiva, como uma superfície lisa a ser "contemplada" apenas. A paisagem se configura como um campo epistemológico construído em escalas discursivas do visual e do imaginário. Ao longo do debate Duncaniano a paisagem ganha a conotação de um sistema de representação, sendo permeada por constructos sociais que variam culturalmente, espacialmente e temporalmente.

Associada à idéia de paisagem na obra de Duncan (2004, p. 100) aparece o enfoque textual e/ou sub-textual. Ele coloca que cabe ao cientista social fazer a leitura dos subtextos presentes nas paisagens-textos: "o significado desses textos e subtextos muda com o tempo e com a mudança de perspectiva do intérprete". Por isso, entendese que uma paisagem é um fenômeno espaço-temporal, continuamente elaborada, e significada por atribuição de valores, de práticas, de fatos, e sobretudo, como uma expressão de diferentes níveis de representação.

Esse autor ressalta ainda que a compreensão da paisagem perpassa a ordem social tanto na atribuição de sentido, quanto no valor simbólico de sua representação. Enfatizando principalmente que, a cultura está embutida em todos os processos de criação e interpretação dos signos textuais que possibilitam a leitura da paisagem, para ele a paisagem é tomada como sendo essencialmente social, como um campo interpretativo de significados culturalmente instituídos.

Uma acepção sobre a dimensão cultural da/na paisagem apresenta em linhas gerais que o conjunto de atitudes, costumes, regras, valores e práticas dão aos grupos sociais as chaves de leitura e/ou apropriação aos aspectos sócio-simbólicos que ligam as ações humanas aos lugares. Tal perspectiva é reiterada nas palavras de Claval (1978, p. 150), quando estabelece que “a geografia não pode ignorar o sentido já vivido [...]. Escutando as sensibilidades, a nova geografia descobre que as realidades regionais que explora existem em primeiro lugar no espírito das pessoas”. 
Assim, considera-se que a leitura da paisagem pode ser feita por diversos prismas. Sendo que, na Geografia Cultural produzida pós 1970, a paisagem tem se configurado campo aberto à problematização ultrapassando as relações diretas entre os interesses econômicos e a produção do espaço. O entendimento feito pela Geografia Cultural sobre essa categoria de pensamento, interrelaciona-se a um processo ocasionado por práticas sócio-culturais de usos, apropriações, percepções e representações. Através das práticas sociais e culturais a paisagem se efetiva enquanto produção e reprodução, sendo permeada por constructos identitários flexíveis. Ao passo que, reconhece-se a importância de pensá-la enquanto uma experiência de mediações, que transcende as determinações individuais, atingindo por vezes, um complexo coletivo de forças antagônicas e complementares.

$\mathrm{Na}$ Ciência Geográfica todas as categorias de análises são formas de representação, e a paisagem, constitui-se como uma das abordagens imprescindíveis para elucidar as formas de apropriação no espaço. Silva (2001) entende que a representação é fruto de um sistema de idéias, quer seja racional, mítico, científico, filosófico e principalmente artístico. A paisagem é uma forma de representação que se estabele enquanto no campo do conhecimento. Mesmo que tempo e espaço gerem determinadas formas de representação, é na dualidade sujeito-objeto que reside o denominador comum que pode conceber toda forma de representação.

$\mathrm{O}$ ato de representar o mundo através de qualquer meio atribui uma carga de valores aos espaços, às formas de morar, às formas de sentir, às formas de convivências entre os grupos. As representações são ao mesmo tempo, aquilo que o sujeito projeta e aquilo que ele absorve nas convivências e/ou experiências coletivas. Assim, a paisagem se coloca como um universo de intenções que tem sentido e significado para os que a praticam. A paisagem associada a narrativas e representações verbais e visuais condensa universos simbólico-imaginários. Na paisagem há uma centralidade de representações atravessadas por movimentos transitórios, em que por vezes se tem nuancias e tensões, por vezes maneiras de apresentar e significar com as quais os grupos inscrevem suas experiências espaciais.

No dizer de Schopenhauer (2001), se tudo o que existe está para o sujeito e depende dele, então o mundo é uma representação. Nas representações emergem apreensões resultantes dos condicionantes fisiológicos, psicológicos, sócio-culturais e econômicos. Oferecendo elementos para o debate da estética, das sensações, dos 
desejos e das práticas de apropriação espacial. Acerca desta questão, Silva (2001, p. 76) expõe que a representação aplicada à temática da paisagem urbana contribui para a compreensão da vida, e do cotidiano citadino que se expressa nos projetos, planos, invenção e construção da paisagem. A representação interrelaciona-se a poderes, saberes e práticas de reconhecimento, e reprodução cultural.

A lógica da representação se coloca como um universo de projeções. Todas as experiências humanas envolvem os indivíduos em um substrato cultural. $\mathrm{O}$ ato de representar o mundo através de qualquer meio atribui uma carga de valores aos espaços, às formas de morar, às formas de sentir, às formas de convivências entre os grupos. As representações são ao mesmo tempo, aquilo que o sujeito projeta e aquilo que ele absorve nas convivências e/ou experiências coletivas.

As formas de representação rebatem nas lembranças, sejam essas recorrências individuais, sejam quadros de orientação coletiva. De tal forma que, ao longo da trajetória humana sobre a Terra, as civilizações elaboraram formas intelectuais, artísticas, morais, materiais e imagéticas capazes de revelar, embora que parcialmente, formas de relacionar-se com o mundo religioso, com as proibições, e as inquietações político-estratégicas. Assim, Tacca $(2005$, p. 12) entende que a representação seja em sua carga simbólica, epistêmica ou estética, uma forma de construção e de conhecimento da vida social.

Associados às formas de representação em escalas individuais e coletivas, os bens simbólicos estão presentes em todas as formas de espacializar-se. Laplantine e Trindade (1997, p. 21) manifestam que é impossível pensar a vida social fora de uma rede de representações. Dessa forma, a realidade só pode ser analisada através da representação. Tanto é que Chartier (1990, p. 18) indica que as representações são matrizes de discursos e de práticas diferenciadas. O mencionado autor revela que, a representação deve ser problematizada a partir das práticas e das apropriações.

O que leva seguidamente a considerar estas representações como as matrizes de discursos e de práticas diferenciadas $-<<$ mesmo as representações colectivas mais elevadas só têm uma existência, isto é, só o são verdadeiramente a partir do momento em que comandam actos $>>$ - que têm por objectivo a construção do mundo social, e como tal a definição contraditória das identidades - tanto a dos outros como a sua (ibidem, p. 18). 
A representação é extremamente rica de significado, de plasticidade, de porosidade, aparecendo, portanto, como uma possível resposta às projeções que os grupos elaboram como equivalentes, para as questões que perpassam a existência da vida social, e por conseguinte da paisagem. Assim, todas as representações dão a conhecer as múltiplas formas de lidar com o espaço. Representar é atribuir sentido a tudo que o humano faz, a tudo que o cerca, a tudo que os sujeitos projetam sobre o espaço. Tal proposta ganha dimensão na obra de Chartier (1990), quando manifesta que:

Por um lado, a representação como dando a ver uma coisa ausente, o que supõe uma distinção radical entre aquilo que representa e aquilo que é representado; por outro, a representação como exibição de uma presença, como representação pública de algo ou de alguém. No primeiro sentido, a representação é instrumento de um conhecimento mediato que faz ver uma $<<$ imagem $>>$ capaz de reconstituir em memória e de o figurar tal como ele é. Algumas dessas imagens são bem materiais e semelhantes, como os bonecos de cera, de madeira ou de couro, apelidados justamente de $<<$ representações $>>$, que eram colocados por cima do féretro real durante os funerais dos soberanos franceses e ingleses e que mostravam o que já não era visível, isto é, a dignidade imortal perpetuada na pessoa mortal do rei. Outras, porém, são pensadas num registro diferente: o da relação simbólica que, para Furetiére, consiste na $<<$ representação de um pouco de moral através das imagens ou das propriedades das coisas naturais [...] O leão é o símbolo do valor; a esfera, o da inconstância; o pelicano, o do amor paternal $\gg$. Uma relação compreensível é, então, postulada entre o signo visível e o referente por ele significado - o que não quer dizer que seja necessariamente estável e unívoca. A relação de representação - entendida, deste modo, como relacionamento de uma imagem presente e de um objeto ausente (ibidem, p. 20-21).

Todas as experiências humanas envolvem os indivíduos em um substrato cultural. $\mathrm{O}$ ato de representar o mundo através de qualquer meio atribui uma carga de valores aos espaços, às formas de morar, às formas de sentir, às formas de sociabilizar entre os grupos e culturas. As representações são ao mesmo tempo, aquilo que o sujeito projeta e aquilo que ele absorve nas convivências e/ou experiências coletivas favoráveis a constituição do imaginário. Sendo que, o imaginário não é constituído apenas daquilo que se vê, mas das memórias que se acolhem e confecçionam ao longo de uma história individuo-coletiva. Silva (2001) ressalta que o imaginário estabelece mediação entre o visto e o vivido, entre representação do real e os universos simbólicos. Associar a idéia de representação a de imaginário é antes de tudo, 
considerar que a realidade sócio-espacial é algo a ser percebida e interpretada. Assim, Laplantine e Trindade (1997, p. 12) afirmam que "o real é a interpretação que os homens atribuem à realidade. $\mathrm{O}$ real existe a partir das idéias, dos signos e dos símbolos que são atribuídos à realidade percebida".

Nesse sentido, o imaginário opera como mediação daquilo que se representa coletiva e individualmente. Porque, as formas de representar correspondem aos significados que se atribui à paisagem, a cidade e as diferentes concepções históricas; quer em relação aos sentidos e imagens que se realizam nas ruas, nas casas, nas praças, nos templos; quer entre o registro e a acumulação de experiências daqueles que praticam esses lugares.

\section{Imaginário: campo de significação da paisagem.}

À medida que a paisagem se dimensiona pelas formas de representação, ela encerra um complexo universo de camadas de significados, dinâmicas de conteúdos e de processos. Desse modo, o conjunto das representações envolve uma reflexão mais complexa da interação entre os sujeitos, e as práticas de sociabilidades espaciais. Com isso, passa-se a estabelecer pontes para compreender a complexidade que reveste o espaço, confiando que as caminhadas por determinados trechos, a negação de outros, como também as relações que se mantêm com o tecido citadino são elementos daquilo que Maffesoli (1999, p. 278) chamou de "geografia imaginária".

Em Maffesoli $(1995,1999,2001)$ há uma experiência do mundo imaginal que avança na pós-modernidade, e o imaginário se constitui muito mais como prática, como um motivo, como um fenômeno que se revigora no cotidiano, no estar junto, enfim, nos sujeitos praticantes da cidade e seus sentimentos coletivos. Por isso, entende-se que para o autor em consideração o imaginário é um "contágio afetivo" (Maffesoli, 1995, p.112) que se faz na experiência do presente. Ao passo que, Castoriadis (1982) avança na concepção do imaginário como elemento instituído e/ou que se institui em um campo de conflitos no/do simbólico-imaginário. A abordagem que o segundo autor trata é profundamente atualizada, principalmente porque as relações sancionadas no processo histórico-espacial são instituídas na vida imaginária-simbólica. Ele enfatiza que o imaginário deve utilizar o simbólico, não apenas como uma expressão pura, mas como princípio de existência e significação. 
Em Castoriadis (1982) o imaginário é um produto de ordem simbólica instituída e que não se reduz ao simbólico pelo simbólico "o simbolismo não pode ser neutro, nem totalmente adequado" (Castoriadis, 1982, p.147), ele ainda ressalta que as instituições não se reduzem ao simbólico, mas, que todas as esferas sociais “constituem cada qual sua rede simbólica. Uma organização dada da economia, um sistema de direito, um poder instituído, uma religião existem socialmente como sistemas simbólicos". Assim, a dimensão imaginária punge o "movimento histórico real, em nosso ciclo cultural grego-ocidental, de conquista progressiva do simbolismo" (Idem, p.153), o imaginário é uma criação incessante e essencialmente indeterminada socialhistórica-psíquica de figuras, formas e imagens.

Todas as experiências do mundo social-histórico-espacial estão entrelaçadas aos campos de força que enredam o imaginário. Os procedimentos individuais e coletivos estão disseminados em uma rede simbólica não homogênea. De maneira que, para Castoriadis (1982, p. 142) o quadro imaginário deriva da linguagem, e se consubstancia nas instituições. A operação simbólica imaginária é associada por Castoriadis (1982) a um campo de criação que se revigora com, na e pela linguagem.

A linguagem está em conformidade com a instituição enquanto condição de existência. $\mathrm{O}$ valor que é atribuído à linguagem em seus significantes e significados influência decisivamente o imaginário. Por isso, é preciso considerar o imaginário numa correspondência simbólica que se defini no campo da leitura, do signo, da mensagem, da comunicação. Segundo o autor, só existe a vida social porque os homens comunicam e cooperam num meio simbólico, "mas esse simbolismo é ele próprio criado. A história só existe na e pela "linguagem" (todas as espécies de linguagem), mas essa linguagem, ela se dá, ela constitui, ela transforma." (Castoriadis, 1982, p.168).

Acredita-se que a concepção dos sistemas simbólico-imaginários concebidos por Castoriadis (1982) se alinha a perspectiva de abordagem da linguagem fotográfica. Sobretudo, porque a imagem fotográfica provoca e permite conceber uma espacialidade, uma memória circunstanciada ideológica e culturalmente. A cartografia visual instituída pela imagem fotográfica se integrada a um capital simbólico, que se faz presente em toda a vida social, na vida familiar, econômica, religiosa e política, alimentando, portanto, formas de reconhecimento da paisagem. 
Desse modo, entende-se que a cartografia visual permeada pelos múltiplos campos imaginários, vincula-se aos significados culturais da paisagem aludidos por Cosgrove (1998, p. 103) principalmente porque ele observa que o significado cultural é introduzido na paisagem, e também pode ligá-la a outros campos simbólicos. A paisagem enquanto representação figura no debate de Cosgrove (2000) como fruto de um trabalho imaginativo e poético. Ao passo que o imaginário seria a capacidade mobilizadora e evocativa. Ele diz que:

[O imaginário] não pertence apenas aos sentidos, que nos alinham à natureza, nem só ao intelecto, que se separa dela. O trabalho da imaginação [do imaginário] não é totalmente reprodutivo (isto é, determinado pelos dados sensoriais extraídos do mundo exterior, do qual ela depende), tampouco puramente produtivo (isto é uma negação das imagens produzidas nesse mesmo mundo). $\mathrm{O}$ [imaginário], ao contrário, desempenha um papel simbólico, capturando dados sensoriais sem reproduzi-los como imagens miméticas e "metamorfoseando-os" através de sua capacidade metafórica de gerar novos significados, a paisagem citadina ganha contornos variados a partir dos significados que lhes são atribuídos, nominalizados e experimentados numa confluência entre vivência, convivência e representação social. A cidade seria uma representação espacial que se completa a partir da intricada relação entre experiências concretas e subjetivas e lugares variados (ibidem, p. 36).

Os mundos simbólicos da paisagem exercem uma força de união na articulação das várias peças que tramadas em proximidade constituem um espaço tesselado por sistemas imaginários. A paisagem detém e aciona tendências e sistemas de valores. Trata-se de um achado do qual permutam agentes sociais, significados, representações e entendimentos imagéticos do mundo vivido. A essa questão Marandola Júnior (2003), diz que os sistemas simbólicos surgem, nesta perspectiva, para unificar o imaginário social, e que sem o universo imaginário as espacializações não ocorreriam, e por extensão, toda e qualquer forma de representação social.

A paisagem se coloca enquanto manifestação identitária, pondo em proximidade e/ou em distanciamento visões de mundo, usos, consumos e processos de apropriação simbólico-afetivo dos lugares. Em se tratando da reflexão evocada, podese associá-la a uma base analógica, onde a cidade seja o labirinto, a paisagem revelada pela fotografia seja um campo aberto transversalizado por representações discursivas, simbólicas, sensíveis e imaginárias. Por isso, as práticas cotidianas, as sociabilidades 
estabelecidas entre os sujeitos praticantes dos lugares contribuem para a constituição imaginária espacial. Portanto, acredita-se que a imagem fotográfica é um poderoso integrante da realidade que fundamenta a leitura e o conhecimento do imaginário da paisagem, evidenciando espacialidades da/na paisagem.

$\mathrm{Na}$ tentativa de desvelar as espacialidades da paisagem citadina que secretam amores, medos, encontros e desencontros, a imagem fotográfica se mostra como o fio condutor para compreensão dos elementos materiais e imateriais que impregnam a paisagem citadina. A paisagem da cidade, ao longo dessa pesquisa, revela-se a partir do diálogo entre imagem e imaginário, cujas relações sociais, culturais, simbólicas e afetivas dão significado à perspectiva da paisagem como construção compartilhada por vários atores, fazeres e saberes.

A imagem da paisagem registrada pela fotografia é uma leitura fragmentada da experiência humana no espaço, leitura essa que promove outras leituras. Ela [a paisagem] não é natural, não é natureza, é antes resultado da acumulação de interpretações, de leituras do mundo, de campos imaginários de sentidos. A paisagem da cidade é parte e parcela das ações direcionadas pelos agentes públicos, pelos sujeitos que tecem suas relações na frivolidade das inclusões/exclusões que anima as estratégias do social. E o fotógrafo se mostra como escritor, que elabora sua versão sobre os elementos que possibilitam interpretar os campos imaginários que a integra.

\section{Paisagem em foco: Jardim do Seridó/RN pelas imagens fotográficas.}

Temporalmente e espacialmente a imagem fotográfica cria redes de significação como operação que se mantém entre o fotógrafo e o resultado que emerge de seu trabalho. Por isso, o resultado dessa criação é entendimento da paisagem. De maneira que, a experiência visual disseminada pela imagem é o resultado das práticas que se refletem em produção de sentidos, de iniciativas, de flexibilidades, de sensibilidades, sem produzir uma identidade universalizante. A paisagem revelada pela fotografia é o lugar das relações simbólico-imaginárias tramadas na argamassa cultural.

Nesse sentido, o trabalho de Zé Boinho, "poeta das luzes" que elaborou uma narrativa visual acerca da vida social de Jardim do Seridó/RN faz a cidade significar em relação ao público e privado, às projeções e perspectivas, ao singular e plural durante os anos de 1950 a 1980. A imagem fotográfica deixada por Zé Boinho é um dispositivo de 
memória espacial, é um poderoso integrante cultural, que aloja uma multiplicidade de informações, e que comunica através de simultâneos cortes o tempo e o espaço.

O acervo imagético, diz de uma Jardim do Seridó/RN como sendo atravessada por um campo visual, em que a espacialidade da cidade é o ponto máximo de referência, é o particular absoluto. De modo que, a espacialidade emerge como obra plástica e estética. Tal proposta, ganha dimensão a partir do investimento que é dado aos sentidos espaciais que inscrevem e fazem parte da trama imaginária instituída pela imagem fotográfica. Haja vista que, ao longo do acervo ela [a paisagem] se situa numa escala de sinuosidades, retas, aberturas, fechamentos, planos, pontos e perspectivas. Assim, a paisagem se estabelece numa intensa relação de elementos, cuja criação estética relaciona um campo que dá a ver a cidade muito mais como poder icônico, do que como flagrante da presença ou ausência de determinados prédios, sujeitos, aparelhos urbanos e grupos sociais.

Zé Boinho (ver figura 01) demonstrou ao longo de sua produção imagética sobre Jardim do Seridó/RN, uma preferência pela expressão de urbanidade que a cidade adquiria em suas transformações conjunturais em suas praças, prédios públicos, avenidas, canalização de riachos, por exemplo. Ademais, operacionalizou uma narrativa visual da cidade como reservatório espacial de significação, sobretudo obtendo a partir da exploração de linhas, de proporções e da disciplinarização da forma um sentido de expansão. Ademais, dada a influência urbana que desponta no acervo, é preciso perceber algumas temáticas, e levantar questões para melhor operacionalização e sistematização dos temas. Sendo preciso problematizar de imediato zonas de significação, por meio dos seguintes pontos: qual o objeto central da narrativa fotográfica sobre Jardim do Seridó/RN? Como determinados espaços estão instaurados no interior da cidade? Em que campo de visão a espacialidade urbana foi enfatizada? 


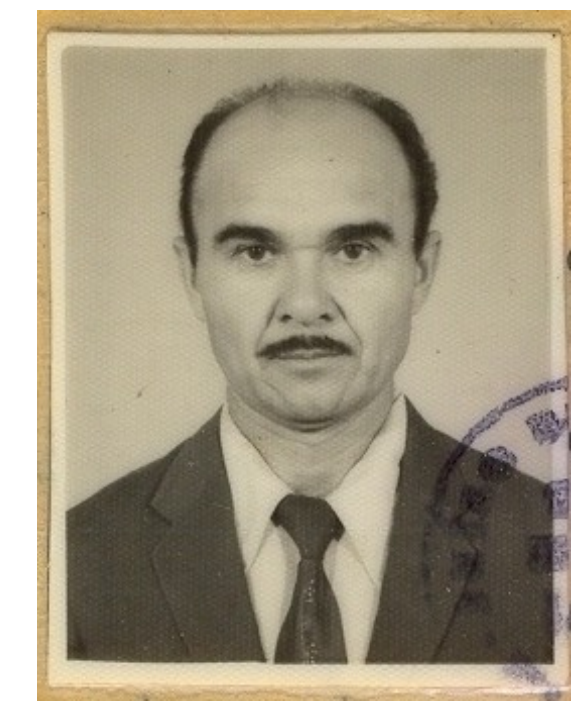

Figura 01: Zé Boinho.

Fonte: acervo pertencente à família do fotógrafo. Jardim do Seridó, 1978.

As indagações elencadas acima não esgotam a reflexão que se tem, mas contribuem como referências para a leitura da paisagem. Principalmente, porque se insiste que a "cartografia visual" integra um poderoso espaço discursivo, envolvendo valores individuais e coletivos. O circuito alcançado pela visualidade cartográfica se coloca enquanto orientação e expressão do campo real-simbólico que figura como espaço projetado dentro, e para além do olhar. Corroborando com a idéia ressaltada desde o princípio, de que além do que se "enxerga" visualmente, conservam-se construções sociais discursivas potencializadas em estratégias de apropriação do espaço. Essa concepção, portanto, favorece o diálogo entre campos imaginários e significados produzidos, sobretudo, na vida cotidiana

Desse modo, confia-se que o exercício profissional que Zé Boinho tangencia é impossível fora de um sistema de significados intertextuais de leitura, interpretação e escrita visual da/na paisagem. Ele apreende uma cartografia real-simbólica da cidade através de formas, dos claro/escuros, sobretudo pela evidência que tem o plano de claridade, ou seja, o dia ao longo da narrativa. Assim, acredita-se que o valor do dia opera em oposição à penumbra da noite ${ }^{2}$. A apropriação da paisagem durante o dia

${ }^{2}$ Foi observado ao longo do acervo que se dispõe - quase trezentas fotografias - a inexistência de imagens da cidade à noite, ou de qualquer evento noturno. Em contra partida, há uma busca incessante pela cidade em sua luminosidade, como mecanismo 


\section{CATELIÊ GEOGRÁFICO REVISTA ELETRÔNICA

valoriza a cidade como experiência do visível (ver figuras 02, 03, 04, 05), como reunião de estéticas produtoras de espacialidades, como estratégia de significação do diurno.

A cidade é uma presença luminosa inteligível que se dar a ver, permitindo recuperar uma projeção de dentro para fora da imagem, como um espaço sem mistérios. Posto que, com a luz do dia tudo é permitido se enxergar: as reentrâncias, as dinâmicas, os segredos, os equipamentos urbanos e os caminhos percorridos para conhecimento da paisagem citadina. Conforme se observa na seqüência de imagens (ver figuras 02, 03, 04, 05), o que se inscreve é uma trajetória do olhar, um espaço preferencial de distanciamento em que se enfatiza o tempo todo, a visualidade como elemento de percepção não encerrado em si mesmo. As paisagens inscritas pela imagem revelam um esforço de abertura do visual no sentido de oferecer a cidade como um mecanismo esquartejado por estruturas, ao mesmo tempo em que não apresenta as coisas como elas são. Essa estratégia permite criar uma composição artística na medida em que se associam formas de selecionar a visualidade.

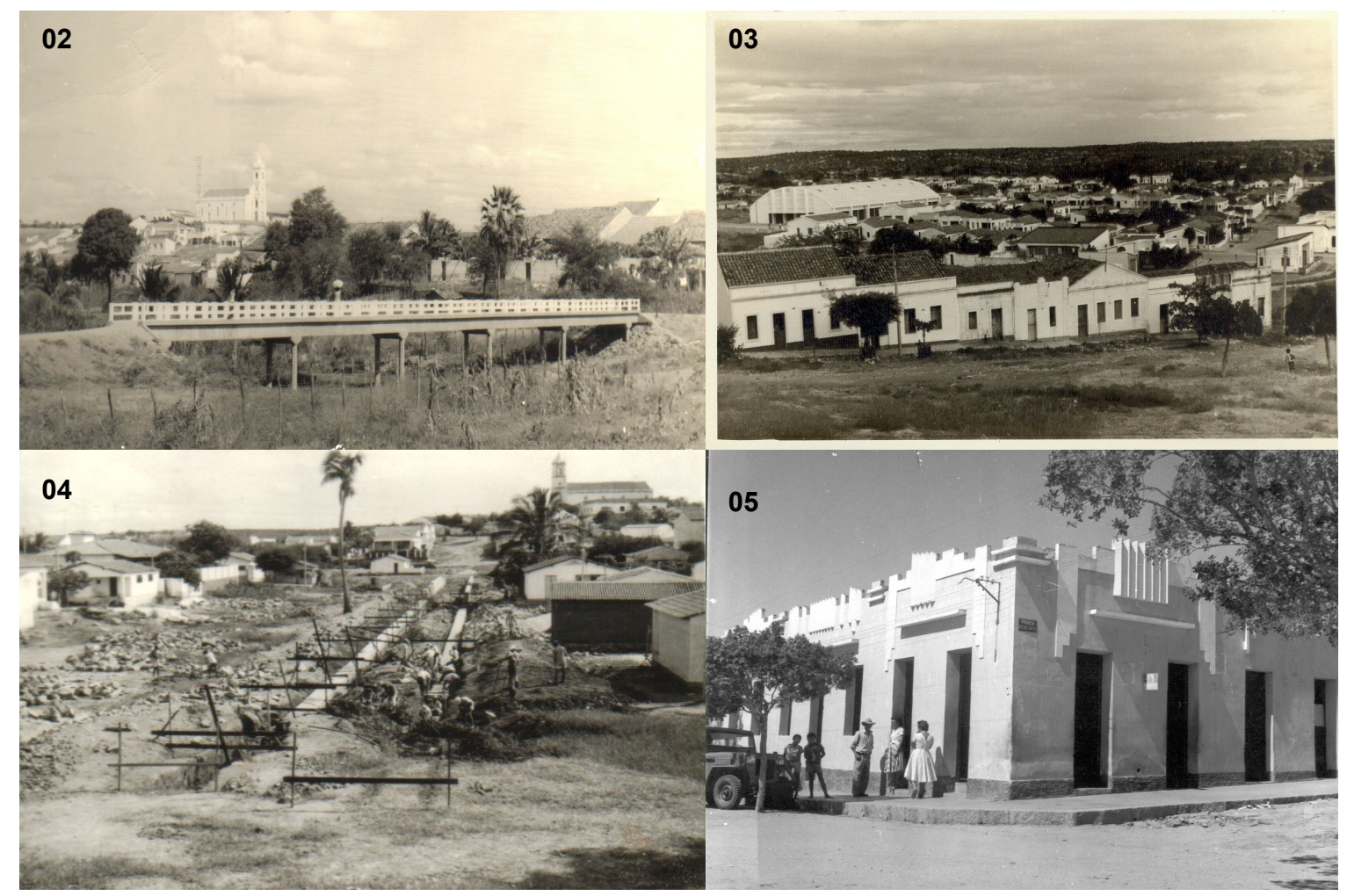

Figuras 02, 03, 04 e 05: Jardim do Seridó: diurnidades da paisagem.

Fonte: Zé Boinho. Acervo pertencente à família do fotógrafo

que se inscreve e atravessa o olhar, sobremaneira a claridade como constante que permite "ver", olhar, enxergar, ler. 
Zé Boinho em sua experiência urbana transversaliza a paisagem a partir da imagem, significando-a estética e simbolicamente. Por intermédio de uma arte-técnica operacionalizada pela abertura do diafragma, do obturador na capituração da luz. Criando um sistema simbólico, cujo conteúdo constitui uma prática, um exercício de várias motivações. A paisagem imagética, por sua vez, permite acompanhar um percurso do fotógrafo com seu lugar ao longo do dia. Em sua espacialidade tangível Jardim do Seridó/RN é uma produção espacial, que se confunde com os ritmos de transformação imagéticos elaborados pelo fotógrafo, numa constante criação. Pois, é por ela [pela cidade] que Zé Boinho cria um ritmo potencializador de sentidos, cujos acontecimentos ora estão no mesmo plano de visão do fotógrafo, ora são espaços que rompem com o fluxo linear do olhar.

Na caminhada do fotógrafo pela cidade despontam lugares, objetos urbanos que se anunciam em forma e em conteúdo. Como um referente que se tem e anuncia enquanto trajetória, como passagem, na medida em que as imagens são fragmentos que integram o espaço urbano (ver figuras 02, 03, 04, 05). Essas imagens fotográficas são correspondências possíveis entre outras cidades inscritas na cidade de Jardim do Seridó/ RN. Como intercruzamento de linguagens, entre o vazio e a plenitude, entre formas e forças enunciativas de uma "realidade" visível. Em que a cidade é sempre uma vista panorâmica em processo de mudanças, em construção.

As imagens fotográficas (ver figuras $02,03,04,05$ ) despertam um sentimento anti-noturno. Já que o exercício fotográfico inscreve a cidade em sua experiência diurna, fortalecendo visualmente o dia em suas evidências tangíveis. Acredita-se que o emprego da luminosidade enfatiza um plano de organização da cidade como escolha do mensurável. Desse modo, a imagem fotográfica se coloca como apropriação do espaço. Posto que, o recorte visual que Zé Boinho faz da cidade se organiza enquanto centralidade do visto, e não necessariamente do modo como os grupos sociais se deixam afetar na/pela cidade. Com isso, tem-se uma paisagem urbana significada por uma ordem de fatores, objetos e fenômenos que foram designados como artefatos urbanos antes mesmo do fotógrafo tematizá-los.

A narrativa criada fotograficamente sobre Jardim do Seridó/RN dissolve diversos ritmos da paisagem enquanto instância pública, enquanto diversidade e sentido geral de espetacularização. O fotógrafo transforma o espaço público em um dispositivo 


\section{CATELIÊ GEOGRÁFICO \\ REVISTA ELETRÔNICA

social que a todos os grupos toca, mas que não há necessidade de particularizá-lo. Desse modo, a cidade aparece como um acontecimento, sendo muito mais um campo aberto, um espaço fragmentado, fragmentador, do que uma cartografia estanque; o visual da paisagem jardinense se faz pelo acompanhamento e transformação em uma espacialidade como além das fronteiras geográficas afetando uma auto-imagem da cidade em sua singularidade, em sua imensa solidão diurna.

É oportuno enfatizar ainda, que a cidade desponta como uma presença material e ao mesmo tempo mutante. Posto que, na tessitura citadina se vê um estado de transformação (ver figuras 06, 07). Por outro lado, com a imagem fotográfica se tem uma cidade se descobrindo permanente como um mundo que se desmancha para o surgimento de outro, como execução plástica. A imagem confere ao processo um valor de ênfase ao plano inferior, quer como uma preferência (ver figuras 06, 07), quer como vazão e prolonga.

A cidade ganha valor estético na medida em que os espaços são revelados sem restrições, como investimento plástico; havendo uma perspectiva fotográfica que a inscreve num plano singular de apropriação. Por isso, as estruturas instituintes da imagem fotográfica revelam uma cidade como experiência visual tramada em um sistema lingüístico que se traduz em imagem, e principalmente como significação da paisagem urbana.

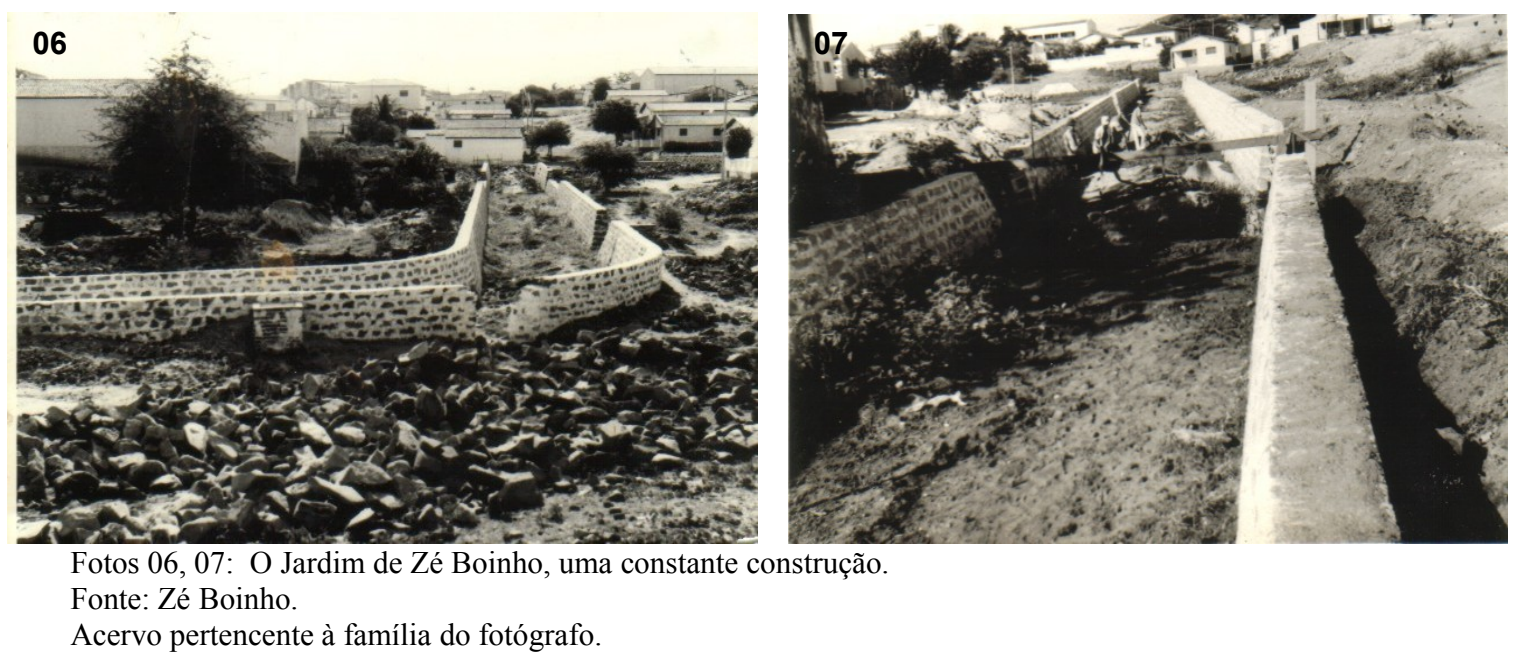

O campo de visão que se tem com essas imagens explicitam a cidade como expressão de um estética específica, mesmo que se reconheça as modificações no espaço estrutural da urbe. Contudo, é preciso enfocar que a cidade fotografada emerge 
em função da visualidade que se tem a partir do alcance projetado pelo resultado compositivo. Há uma preocupação do fotógrafo em evidenciar determinadas linhas de fulga, criando um eixo de alcance que se projeta como campo de exploração do horizonte.

Os acessos que se tem da cidade pela cartografia visual integram uma composição espacial da paisagem jardinense, como simetria que se institui em um campo de forças imaginárias. Traduzindo sentidos de apropriação espacial com os quais se pode acessar a realidade e enxergá-la desta ou daquela forma. "Pois o imaginário é esse motor de significados à realidade, é o elemento responsável pelas criações humanas, resultem elas em obras exeqüíveis e concretas ou se atenham à esfera do pensamento ou às utopias que não realizaram, mas que um dia foram concebidas." (Pesavento, 2007, p.12). Por isso, o acervo fotográfico de Jardim do Seridó, decorrente do exercício de Zé Boinho, é sobretudo, resultado de uma sensibilidade imaginativa operacionalizada sobre a paisagem.

Assim, a imagem e o imaginário se mostram como pontos de subjetivação das visibilidades individuais e coletivas da urbe jardinense, (retro) agindo nos entendimentos e valores culturais, por conseguinte, na paisagem. Essa última referência mostra-se como resultado de uma construção simbólica, carregada de significados variados, cotidianamente apropriada pelas táticas dos grupos sociais que incorporam sentido ao espaço. Desse modo, o conceito de imaginário trabalhado por Castoriadis (1982) consegue aproximar e/ou distanciar as linhas simbólicas que tramam o tecido citadino circunstanciado pela imagem fotográfica. O imaginário que se arvora como campo de instituição do social, como atmosfera relacional indica uma infinidade de códigos, de sinais e de signos que embasam a memória, e que o humano se apropria dando sentido às experiências relativas ao morar, ao entretenimento, aos atos de devoção, às representações ligadas à paisagem. De maneira tal, que se constróem múltiplas relações entre as expressões plásticas e os campos do saber que pungem a paisagem, sugerindo à imagem um campo de significação real-simbólico.

Ademais, ainda como forma de ter acesso ao conjunto urbano capturado pelo "ato fotográfico" construído por Zé Boinho, toma-se o entendimento da imagem fotográfica como discurso, escrita, texto iluminado/luminoso em que operam fragmentos de uma paisagem pulsante. De modo que, "por mais congelada que se (re) 
vele uma imagem fotográfica há nela uma pulsão familiar" ${ }^{3}$. Sendo valoroso elucidar que a proposta da qual se compartilha é a de que a familiaridade da imagem fotográfica se baseia e está diretamente ligada à bagagem cultural de quem a pratica. Acredita-se que por meio da cartografia imagética se tem acesso a campos de memória e dispositivos culturais, que alojam uma multiplicidade de informações, permitindo comunicar através do tempo e do espaço. Nesse aspecto, a paisagem urbana opera como significado e representação social. A paisagem não é simplesmente um reflexo da realidade, mas uma reunião de significados intertextuais que devem ser entendidos em face de outras representações "na paisagem, nós estamos lidando com um produto cultural" (Cosgrove, 1984, Apud Costa, 2002, p.65).

Nesse aspecto, a interpretação imagética do acervo em que se procura evidenciar um único tema: a paisagem urbana, é um processo de revista, de reapropriação discursiva, que adquire sentido se associado aos fragmentos de significados que retrata a imagem fotográfica. A discursividade da imagem possibilita pensar representações coletivas, cujas influências maiores da narrativa visual são os modos como os grupos exprimem suas sociabilidades e se manifestam na paisagem. No que tange a essa questão, confia-se que as imagens fotográficas projetam o espaço citadino numa ordem de fatores que simbolizam quadros de orientação coletiva.

De antemão, é preciso destacar um tópico temático da paisagem citadina (A Rua) que sucede ao longo do acervo. Em se tratando desse objeto urbano, desenvolve-se uma linha de raciocínio que aborda as imagens fotográficas sobre a rua como forma, conteúdo e continente de uma apropriação e significação espacial intencional, que dá a conhecer pontos de subjetivação da cidade. Cada imagem sugere um espaço que se abre a múltiplas formas de entendimento, de criação, e de significação da paisagem. Por isso, se tem uma paisagem como estética inacabada e a imagem fotográfica é sempre uma concepção de paisagem, que domina o homem com uma normatividade despótica; mas é também aquilo que deve ser excluído ou reduzido ao silêncio (Foucault e Rouanet, 1996, p.13).

\footnotetext{
${ }^{3}$ Frase capturada de uma das falas de Muirakytan Kennedy de Macêdo, em sua defesa pública da tese: "Rústicos Cabedais: patrimônio familiar e cotidiano nos sertões do Seridó (século XVIII)", junto ao Programa de Pós-Graduação em Ciências Sociais/ CCHLA/UFRN. No dia 12 de junho de 2007, tendo início as 14:00h, estendendo-se até as 18:00h.
} 
Nesse artigo, o acervo fotográfico foi dividido em um eixo de significação denominado de "A RUA: Campos imaginários da paisagem", acerca desse tópico temático reflete-se sobre o campo de visão temporalizado no discurso fotográfico, sendo que aqui a rua desponta mais como valor estético, do que meramente como espacialidade que possibilita o reconhecimento de uma "realidade da vida urbana".

\section{- A RUA: Campos imaginários da paisagem.}

O imaginário preso às imagens fotográficas se impõe como fresta transposta por significados, sendo inevitavelmente possibilidade de ver, rever, apropriar e reapropriar o circuito comunicativo da linguagem visual. Para entendimento do discurso textual e sub-textual da paisagem, é profundamente valoroso ressaltar o campo de visão simbólico que há na montagem das experiências da paisagem citadina. Desse modo, a opção é considerar as estruturas e as perspectivas da imagem fotográfica, cujas implicações recaem na composição da narrativa imagética enquanto processo de identidade $\backslash a$ lteridade.

Na paisagem há uma construção discursiva em que se associam vontades de "ver". Exemplo disso pode ser acompanhado nas pinturas do medievo e renascentistas, que criaram uma perspectiva de existência para a cidade a partir do ponto de vista panorâmico, essa concepção plasma o campo de significação da paisagem. As pinturas medievais ou renascentistas representaram a cidade vista em perspectiva, por um olho que não existia até então (Certeau, 2003, p. 170-171). O expraiamento da paisagem citadina numa concepção panorâmica, que advém do movimento de idéias renascentistas, promove uma profunda mudança nas convenções sociais de representação do espaço, bem como no próprio sentido da prática espacial, das/nas sensibilidades cartográficas que se criam.

Ao passo que, "olhar" a paisagem da cidade envolve um campo de visão intertextual denso, em que mecanismos urbanos, como por exemplo a rua, constitui-se em campo de interpretação e significação, histórico, social e culturalmente constituído. Desse modo, é favorável proceder à leitura da paisagem a partir das seguintes questões: Qual a estrutura imaginária da rua na composição da paisagem citadina? Que valores estão associados aos domínios da rua? Como a rua está representada pela/na cartografia imagética jardinense? 
Responder essas questões é uma tarefa que envolve a percepção da estrutura imagética, bem como, a compreensão do texto visual ${ }^{4}$. A sociedade ocidental atravessou parte do século XIX, vivenciou o século XX e adentrou o XXI, numa produção e consumo exagerado, ininterrupto, incisivo de imagens do "mundo real" e do "mundo ficcional" (Costa, 2005, p. 44). Todavia, o exercício pleno de compreensão imagética seja ela (fotográfica, televisiva, videográfica), requer uma "alfabetização visual" enquanto campo de saber.

Os questionamentos aludidos acima funcionam mais como mecanismos de orientação, como mediação de leitura da linguagem visual; em que se associam duas chaves de significação. Deste modo, para dar continuidade ao propósito de compreensão da paisagem por meio da imagem fotográfica, é valoroso demonstrar aqui a maneira pela qual a paisagem jardinense se faz discurso. Sendo necessário considerar de antemão, dois campos imaginários que se cruzam intensamente: I) a rua, enquanto expressividade de usos e desusos, acontecimentos e práticas; II) os ângulos de direção que o objeto urbano [a rua] representa na paisagem citadina. Da relação entre essas duas chaves de leitura, é valoroso atentar para os campos de visão e/ou eixos de sentido de projeção visual, que Zé Boinho cria como parte e parcela na constituição da cartografia imagética da cidade.

Em todo o discurso imagético que Zé Boinho inventaria visualmente do tecido citadino, a rua é o lugar onde se evidencia um sentido de permanência solitária, da

\footnotetext{
${ }^{4}$ Dondis (1997, p.1) considera que a invenção da câmera e as demais formas paralelas de extensão do visual (televisão, cinema, fotografia, computador, etc.), não cessam de se desenvolver, criando "uma necessidade que a muito tempo se faz sentir" de alfabetismo visual. Para o autor, há um imperativo que se precisa tornar acessível na leitura do texto visual [a fotografia], haja vista que "A expressão visual significa muitas coisas, em muitas circunstâncias e para muitas pessoas. É produto de uma inteligência humana de enorme complexidade, da qual temos, infelizmente, uma compreensão rudimentar" (p.2). Ainda nessa concepção, Dondis (1997, p.3) ressalta que para ser considerado alfabetizado verbalmente há necessidade de compreensão e assimilação de uma gama de componentes básicos da linguagem escrita: as letras, os pontos, as concordâncias verbais, e demais códigos da comunicação; ao passo que na alfabetização visual o princípio é o mesmo. Predomina na linguagem visual um sistema básico de aprendizagem de códigos, de sinais, de estruturas significantes-significadas.
}

5 Sobre a pertinência do exercício de leitura que envolve a linguagem fotográfica é valoroso conferir os trabalhos de: Dantas (2003); Kossoy (2001); Dondis (1997) e Costa (2005). 
quase inexistência da presença humana, da plenitude do estar sozinho na cidade. Mesmo que esse espaço [a rua] tenha sido pensado ao longo dos debates urbanos como lugar construído para vivências coletivas.

A narrativa fotográfica aqui pensada (ver figuras $08,09,10,11,12$ ) enfatiza muito mais o objeto urbano [a rua] como forma estética, do que como valor de uso, da presença humana, do fluxo contínuo, embora, usualmente exista um campo comum de compreensão da rua como lugar das práticas cotidianas, que significam e instituem o imaginário da urbe, e a rua se coloque como instância maior de representação dos verbos caminhar, praticar e vivenciar as diversas formas espaciais da cidade sendo então potencializada pelos sujeitos que impõem uma lei de consumo ao espaço (Certeau, 2003, p. 45). O circuito de representação da urbe faz com que a geografia da rua se coloque como obra coletiva, como lugar das práticas, no nível do sujeito que a vivencia. Desse modo, a paisagem da cidade, aparece de maneira geral, enquanto realidade social, como campo aberto que dá conta de inúmeras estruturas onde se inserem múltiplas convivências.

A rua se coloca como possibilidade de percurso, que se faz elou se precisa fazer pela cartografia citadina, como uma forma de reconhecimento da paisagem, na medida em que essa [a rua] atua como primeiro elemento de desvendamento da cidade, não apenas na construção da paisagem, também na medida em que é uma forma de discurso, reticulada por relações de poder. A rua para Damatta (1997, p. 48) se estabelece enquanto categoria sociológica, não apenas como espaço geográfico ou união de coisas físicas comensuráveis, acima de tudo como esfera da ação social, demarcada por atitudes, gestos, assuntos e papéis sociais.

A rua contém elou é continente de uma rede de significados, sendo que por instantes os sujeitos praticantes da cidade experimentam perdas e encontros por entre as "veias" propulsoras da cidade, ou seja, a rua é o espaço da possibilidade do encontro, da transgressão, da descoberta do "outro". Por outro lado, a rua se institui no imaginário citadino como lugar de todos, e de nenhum. A rua não existe como espaço de domínio particular, ela se mantém num fluxo constante de apropriações. Pensar a rua é se deixar atravessar por uma unidade coletiva em que se tem um espaço de apropriação, cujas dinâmicas são sempre formas de mediação, entre o geral e o particular, entre usos e sentidos diversos, obrigando-nos a praticar formas de reconhecimento. A rua é fascínio, é fascinante, porque é nesse espaço que se têm formas de centralidades sempre 


\section{CATELIÊ GEOGRÁFICO

ressurgentes. Na trama imagética da paisagem a rua se revela simultaneamente como possibilidade de abertura, de trânsito, de continuidade, como espaço que dá a conhecer a cidade.

Numa seqüência de fotografias (ver figuras 08, 09,10,11,12) de Jardim do Seridó/RN, é dado a conhecer as ruas da cidade enquanto espaço valorizado em perspectiva, como resultado compositivo em que se busca equilibrar simetrias e linhas de profundidade do texto fotográfico, o fotógrafo opera na contramão do sentido instituído usualmente a rua. Zé Boinho enfatiza a rua como panorama, como campo aberto a ser olhado, como estética própria. Através do foco da objetiva ele cria, captura, "congela" as espacialidades da rua sob o ponto de vista em posição inferior ao plano. De maneira a particularizar as especificidades de um ângulo de visão reto, simétrico e profundo. $\mathrm{O}$ alvo de referência da/na paisagem converge simultaneamente para um ponto de fuga na linha do horizonte, bem como para um sentido de "limpeza" visual da rua; o fotógrafo baixa a câmera para enfocar o campo de visão em ângulo inferior enfatizando a percepção perspectiva da paisagem. A rua no exercício fotográfico desponta como seqüência visual renovada, em que conta e reitera uma dinâmica apropriativa do plano inferior, criando com isso, um sentido de enquadramento. Sendo que por mais que haja um close no plano inferior se tem uma tomada que captura de uma só vez linhas horizontais, criando um sentido de profundidade do que se vê.
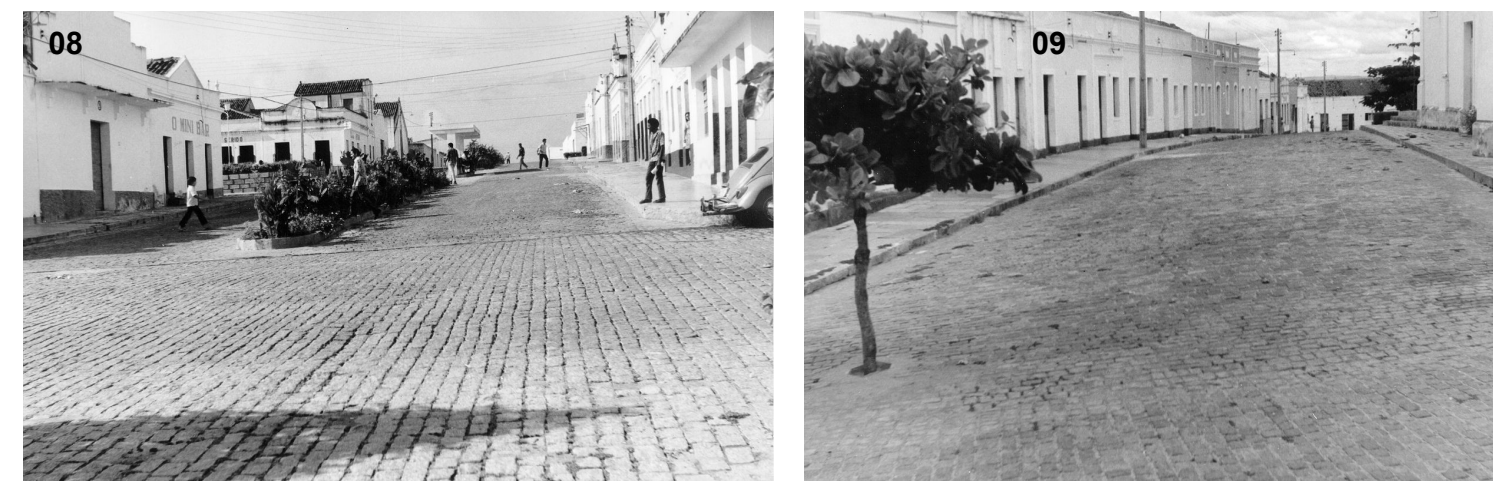

Fotos 08, 09, 10: Jardim do Seridó Ruas em evidências

Fonte: Zé Boinho. 196?, 197?, 198?. Acervo pertencente à família do fotógrafo.

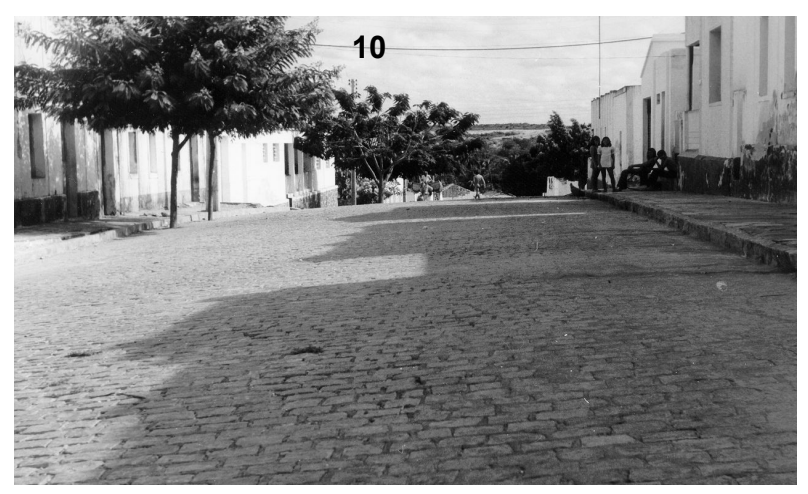


O texto fotográfico dispõe de uma paisagem como perspectiva, em que emerge a rua estruturada em ângulos paralelos na linha do horizonte. O corte, a seleção, as escolhas feitas quanto à constituição das imagens fotográficas, com as quais se (re) conhece e ou (des) conhece pontos de subjetivação da paisagem, evidencia a profunda relevância que teve as ruas da cidade na cartografia visual-simbólica da urbe jardinense, não apenas como construção da paisagem articulada ao domínio da estrutura urbana, mas também, na medida em que projeta e constrói uma nova forma de ver/olhar a paisagem citadina.

Ruas vazias, ângulos paralelos entre calçadas, projeções de profundidade, "limpeza" visual na composição, favorecimento da horizontalidade panorâmica, esses fatores são basilares em toda a narrativa operacionalizada na cartografia da cidade construída por Zé Boinho. E isso, é o que mais chama atenção na composição visual da rua. Essas tomadas (ver figuras 08, 09, 10, 11, 12) significam muito mais o espaço da rua como "ponto de vista", como acontecimento estético, em torno do qual se tem acesso a um particular absoluto.

A imagem fotográfica disposta numa articulação de elementos visuais antecipa informações a respeito do lugar, na medida em que conduz o olhar dentro e para além das inúmeras fronteiras que a espacialidade da cidade é continente e/ou contém. A forma que a paisagem ganha no texto visual, corresponde a uma representação decorrente da valorização que se faz de campos de força abertos em si mesmos (proporção, linhas, pontos, dentre outras técnicas de composição visual). Ao passo que, o resultado compositivo, é decorrente de uma maior importância que se atribui a um componente específico.

A operação imagética que Zé Boinho institui para a cartografia da cidade deixa em evidência o campo de visão da imagem fotográfica, como associação simétrica entre linhas e retas; enquanto isso, o plano compositivo da paisagem se mostra como captura imediata do olhar em seu plano inferior, no "foreground". O olhar que observa a paisagem da cidade atua como agente cartográfico, operando a partir da experiência visual comunicada sociohistoricamente. De tal forma que, a perspectiva do discurso imagético constitui um campo de forças e sentidos espaciais contundentes, alimentando esferas simbólicas. 

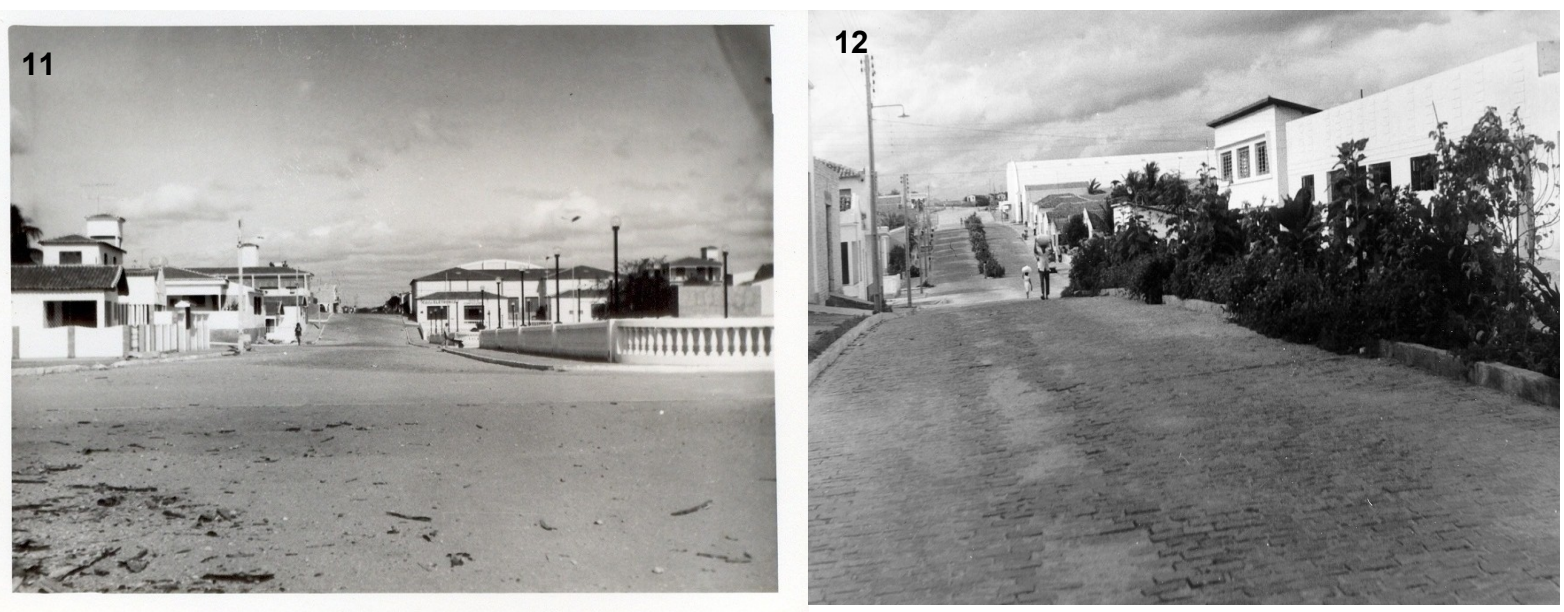

Fotos 11, 12: Espaços da cidade: a rua na cartografia jardinense.

Fonte: Zé Boinho. 196?, 197?, 198?.

Acervo pertencente à família do fotógrafo.

Por isso, o panorama que se tem com as imagens fotográficas em questão, é um esquema de construção da paisagem como imperativo de enquadramento, em que o sentido da rua está posto no movimento que se faz de baixo para cima, de fora para dentro do texto imagético. Desse modo, o referencial comum de constructo verticalhorizontal, constitui a relação básica entre os sujeitos e suas relações espaciais.

A produção/consumo estético da rua corresponde a circuitos discursivos articulados a um contexto específico de composição. A imagem fotográfica além de evidenciar "imaginações geográficas dos indivíduos" (Costa, 2006, p. 41), determina uma posição particular de quem a representa. Desse modo, a espacialidade da rua presente nas fotografias (ver figuras $08,09,10,11,12$ ) tem caráter enfático de frontalidade, com perspectiva de continuidade da ambiência urbana. Assim, a horizontalidade, a frontalidade e a continuidade do campo discursivo que se estabelece na imagem fotográfica deriva de forças simbólicas, que intertextualizam a representação da rua como espaço de operacionalização de valores, maneiras de "ver" "concretasficcionais" na trama da paisagem.

O texto visual integrante de cada uma das imagens (ver figuras 08, 09, 10, 11, 12) retroalimenta circuitos espaciais da cidade como referências estéticas da paisagem, elementos pouco referendados nos estudos urbanos, mas não menos importantes do que os suportes materiais instituintes da espacialidade citadina. Desse modo, a rua, disposta num plano visual e fotográfico, a título de ênfase, vale como forma e entendimento fundamental no desenvolvimento de uma "cultura do espaço" (Costa, 2006, p.36). 
Há uma concepção de rua que vigora profundamente como verticalidadehorizontalidade, ao passo que a referência de entendimento do discurso imagético da paisagem jardinense contempla um ponto de profundidade que se coloca na linha do horizonte. Uma perspectiva que cria o tempo todo, a emergência de profundidade da paisagem. Assim, tem-se uma tentativa de valorização/criação do imaginário geográfico urbano como sendo um investimento narrativo do espaço "que é visto", através do qual se identificam e reproduzem valores (Name, 2006).

\section{Considerações Finais}

O campo de visão da paisagem que se tem a partir das imagens fotográficas deixadas por Zé Boinho, sobre a cidade de Jardim do Seridó/RN permite ter acesso a uma paisagem urbana como conjunto de elementos plásticos que (re) escrevem o espaço citadino como achado visual simbólico, imaginário, "real", "ficcional". O acervo fotográfico dá conta de um universo profundamente estético, numa composição de narrativas e dramaturgias criativas sobre determinados espaços da cidade como: a rua, a igreja, o mercado e o plano arquitetônico.

O fotógrafo manipula e domina com maestria todo um conjunto de técnicas da narrativa visual. Havendo em todo acervo implicações máximas ligadas ao processo de significação da paisagem como função, plano e simetria retroalimentada por processos socioculturais do mundo social. Por exemplo, o sentido da fotografia no domínio da rua desponta na contramão das evidências, das usualidades, do sentido sociológico de produção compartilhada; ainda é preciso considerar que o espaço da cidade vale como existência própria, como ramificação de um dizer que per se basta, na medida em que se revela como um espaço demarcado por estruturas narrativas da linguagem visual.

O acervo fotográfico da paisagem deixado por Zé Boinho é uma forma particular de "olhar" a cidade, uma composição que cria imageticamente sentidos sobre um conjunto de formas, linhas, simetrias operacionalizados em sentidos pretendidos, expressando uma paisagem atravessada por campos de poder, de desejos, de jogos de sentidos. Logo, a leitura e escritura feita da imagem fotográfica é da ordem intertextual, na medida em que a operação que se procede ao longo desse trabalho verticaliza uma paisagem como campo aberto a várias interpretações. 


\section{Referências Bibliográficas}

CASTORIADIS, Cornelius. A instituição imaginária da sociedade. Tradução Guy Reynaud. Revisão Técnica de Luiz Roberto Salinas Fortes. - Rio de janeiro: Paz e Terra, 1982. ( Coleção Rumos da Cultura Moderna, Volume 52);

CERTEAU, Michel de. A invenção do Cotidiano I: as artes de fazer. Trad. Ephraim F. Alves. Petrópolis - RJ: Vozes, 1994. Nova edição estabelecida e apresentada por Luce Girard. $9^{a}$ ed. 2003;

CLAVAL, Paul. A Geografia Cultural. 2. a Ed. Florianópolis: Editora da UFSC, 2001;

A nova Geografia. Tradução Felipe Machado, 1978;

CHARTIER, Roger. A História Cultural: entre práticas e representações. Tradução Maria Manuela Galhardo. Bertrand Brasil, 1990;

COSGROVE, Denis E. Mundos de significados: Geografia Cultural e Imaginação. In.: Geografia Cultural: um século (2). Tradução de Tania Shepherd. - Rio de Janeiro: EdUERJ, 2000, p. 33-57;

A Geografia está em toda parte: cultura e simbolismo nas paisagens Humanas. In.: Paisagem, Tempo e Cultura. CORREAA, Roberto Lobato; ROSENDAHL, Zeny. (org.) Rio de Janeiro: EdUERJ, 1998;

COSGROVE, Denis E.; JACKSON, Peter; Novos rumos da Geografia Cultural. In.: Geografia Cultural: um século (2). Tradução de Tania Shepherd. - Rio de Janeiro: EdUERJ, 2000, p. 18-26;

COSTA, Maria Helena Braga e Vaz da. Espaço, Tempo e a Cidade cinemática. In: Espaço e Cultura. UERJ/RJ. No. 13, p. 63-75, jan./jun. de 2002;

A cidade como cinema existencial. In.: RUA - Rev. De Urbanismo e Arquitetura. Salvador. Volume 1, número 10. Jul/dez. 2006. Semestral. ISSN: 0103-1651. p. 34-43;

. Geografia Cultural e Cinema: práticas, teorias e métodos. In.: Geografia: temas sobre cultura e espaço. CORREA, Roberto Lobato; ROSENDALH, Zeni.(Org.) Rio de Janeiro: EdUERJ,2005. p. 43-78;

As paisagens urbanas e o imaginário fílmico. In: Espaço, Cultura e Representações/ Organizadores Márcio M. Valença e Maria Helena Braga e Vaz da Costa - Natal/RN: EDUFRN - Editora da UFRN, 2005. p. 81 - 95;

DA MATTA, Roberto. A casa e a Rua. 5 ed. - Rio de Janeiro: Rocco,1997;

DANTAS, Eugênia Maria. Fotografia e Complexidade: a educação pelo olhar. Tese de Doutorado apresentada ao Programa de Pós-Graduação em Educação, pela UFRN/CCSA. Natal/RN, 2003;

DONDIS, Donis, A. Sintaxe da linguagem visual. Tradução Jefferson Luiz Camargo. - 2a ed. - São Paulo: Martins Fontes, 1997. (Coleção a); 
DUNCAN, James S. Supraorgânico na Geografia Cultural Americana. In.: Revista Espaço e Cultura - no 13 - dezembro de 1996. Rio de Janeiro: UERJ/NEPEC Semestral; jan./jun. de 2002; p.7-27;

Após a guerra civil: reconstruindo a Geografia cultural como heterotopia. In.: Geografia Cultural: um século (2). CORREA, Roberto Lobato; ROSENDAHL, Zeny; (Org.). Tradução de Tânia Shepherd. - Rio de Janeiro: EdUERJ, 2004;

- Paisagem como sistema de criação de signos. In.: Paisagens, Textos e Identidade. CORREA, Roberto Lobato. ROSENDAHL, Zeni. (Org.) Rio de Janeiro: EdURJ,2004. p.91-144;

FOUCAULT, Michel. ROUANET, Sergio Paulo; et all. O homem e o discurso (A arqueologia de Michel Foucault). 2a ed. Tempo Brasileiro. Rio de Janeiro/RJ. 1996, (Coleção Comunicação 3);

LAPLANTINE, François; TRINDADE, Liana. O que é Imaginário - São Paulo: Brasiliense, 1997. - Coleção Primeiros Passos. No 309;

MAFFESOLI, Michel. No fundo das aparências / Michel Maffesoli. Tradução de Bertha Halpern Gurovitz. - Petrópolis, RJ: Vozes, 1999;

A conquista do presente. Michel Maffesoli. Tradução Alípio de Sousa Filho, Natal/RN: Argos, 2001;

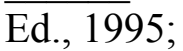

A contemplação do mundo/ Michel Maffesoli. Porto Alegre: Artes e Ofícios

MARANDOLA JÚNIOR, Eduardo. "Londrinas" invisíveis: percorrendo cidades imaginárias. Trabalho de conclusão de curso em Geografia, na Universidade Estadual de Londrina, 2003;

NAME, Leonardo. Escalas de representação: sobre filmes e cidade, paisagens e experiências. In.: RUA - Rev. de Urbanismo e Arquitetura. Salvador. Volume 1, número 10. Jul/dez. 2006. Semestral. ISSN: 0103-1651. p. 44 - 54;

PESAVENTO, Sandra Jathay. Cidades visíveis, cidades sensíveis, cidades imaginárias. In.: Revista Brasileira de História. Órgão Oficial da Associação Nacional de História. ANPUH. São Paulo. Dossiê Cidades. Vol. 27. nº. 53. Jan. - jun. 2007. Abertura, p. 11 23; ISSN: 0102-0188;

SCHOPENHAUER, Arthur. 1788-1860. O Mundo como vontade e representação III. Tradução de Wolfgang Leo Maar e Maria Lúcia Mello e Oliveira Cacciola. - São Paulo: Abril Cultural, 1980. Coleção Pensadores;

SHAMA, Simon. Paisagem e Memória. Tradução Hildegarda Feist. - São Paulo: Companhia das Letras, 1996;

SILVA, Valéria Cristina Pereira da. Representações da Cidade. In.: Formação, Revista da Pós-Graduação em geografia da Faculdade de Ciências e Tecnologia da UNESP. N. ${ }^{\circ} 1-8$ (1994-2001), p.75 - 86. ISSN1517-543x;

TACCA, Fernando de. Imagem fotográfica: aparelho, representação e significado. In.: Psicologia \& Sociedade. 17 (3). Set./Dez. 2005, p. 09 -17;

KOSSOY, Boris. Fotografia e História. São Paulo: Ática, 2001. 